\title{
Thermogravimetric analysis of co-pyrolysis of coal and waste and used tires
}

\author{
Danlu Pan, Weiguo Pan*, Weiting Jiang, Wenhuan Wang, Jian Wang and Yiqing Yang \\ College of Energy and Mechanical Engineering, Shanghai University of Electric Power, Shanghai, 200090, P. R. China \\ Shanghai Engineering Research Center of Power Generation Environment Protection, Shanghai, 200090, P. R. China
}

\begin{abstract}
Waste tires can be used as a substitute for coal due to the high calorific value. In this study, the co-pyrolysis characteristics of the waste tires (truck tires, liners and nylon tires), pulverized coal and their blends are studied using thermogravimetric analyzer. The pyrolysis of truck tires, liners and coal is characterized by a three stages reaction while the pyrolysis of nylon tires and their blends are four stages. The pyrolysis characteristics of the blends can be expressed by the superposition of the pyrolysis characteristics of the one-component material, indicating the slight interaction of the co-pyrolysis between the waste tire and the coal. The co-pyrolysis kinetics of waste tires, coal and their blends are also investigated. For the blends of coal with truck tires and liners, the increased content of coal reduces the activation energy in the 2 nd stage and leads to an increase and then a decrease in the 3 rd stage. Different from the former, the activation energy increases with the increase of tire powder in both the 2 nd and 3rd stages in the blends of coal and nylon tires. This is attributed to the fact that the nylon tires contain more synthetic rubber than truck tires and liners.
\end{abstract}

\section{Introduction}

The rapid development of the economy has led to an increase in energy consumption. As the most important energy source, fossil fuels are gradually decreasing [1]. People are actively working on new energy research to ease energy shortages. Ke-Miao $\mathrm{Lu}$ et al. found that that biomass can be used as a fuel to replace part of the coal, and its properties can be improved by baking [2]. Liao et al. showed that the ignition characteristics can be improved when the sludge is blended with coal for combustion. They also noted that the blends have similar combustion characteristics to coal when the sludge content is low [3].

Economic growth has brought many environmental problems. The developed automobile technology and well-connected road network have made people's life become convenient. However, the occurrence of a large number of used and waste tires has created new troubles. According to the statistics of the World Health Organization, the world's waste tires have accumulated 3 billion, while still growing at an alarming rate every year [4-7]. In 2017, the amount of used tires in China was about 340 million, and the weight was more than 13 million tons [6].

Used tires as one of the sources of solid waste, known as "black pollution" [8]. Its recycling and processing technology has always been a worldwide problem. Different from ordinary municipal solid waste (MSW), the main component of waste tires is a nondegradable polymer material, which is very difficult to handle and requires more than 100 years of microbial decomposition $[9,10]$. Moreover, the accumulation and long-term open-air storage of used tires will occupy mass land resources, breed mosquito-borne diseases, deteriorate natural environment, cause fires and threaten people's lives and property [11-14]. It has been attracted wide attention to explore new ways to deal with used tires.

The main chemical components of the tires are natural rubber and synthetic rubber. In addition, the tires also contain many hydrogen and carbon materials, including copolymer, nylon, polyester, sulfur, carbon black and so on [15-18]. Compared with coal, waste tires have a higher calorific value (29 40MJ/kg) [11], which is considered to be an attractive potential fuel. As a fuel treatment, it is undoubtedly a promising clean process. Furthermore, the moisture content of tires is very low compared to alternative energy sources such as biomass or municipal solid waste (MSW) [11]. Therefore, used tires are a kind of energy with high value.

Co-combustion of coal and used tires can improve the thermal efficiency of the boiler [14]. Therefore, using used tires as a supplementary fuel mixed with pulverized coal is an effective method for treating waste tires. The release process of pyrolysis volatiles from the waste tire rubber powder (hereinafter referred to as rubber powder), coal powder and their blends has an important influence on combustion. An accurate description of its volatile release process is conducive to the efficient use of fuel. The pyrolysis of used tires has been extensively studied [19-21]. Pyrolysis of used tires is carried out without

\footnotetext{
* Corresponding author: pweiguo@163.com
} 
oxygen (inert atmosphere or vacuum) [19,22]. Many scholars have studied the pyrolysis characteristics of rubber powder. The research results vary with the tested sample, instrument, and experimental conditions. Martinez et al. extensively described the pyrolysis parameters of waste tires and the effects on product yield and composition [19]. Aylón et al. compared the effect of reactor type on yield and product properties [20]. Juan Daniel Martínez et al. predicted the syngas composition, reaction temperature and some process parameters by changing the equivalence ratio (ER) and steam-fuel ratio (SF) according to the mass and energy balance and stoichiometric equilibrium model. The effect of pyrolysis temperature on the composition of volatile matter and coke was also studied [21]. However, relatively little study has been conducted on the joint pyrolysis of pulverized coal and rubber powder. Therefore, the pyrolysis characteristics of the rubber powder will be analyzed by thermogravimetric analyzer in this study, as well as the blends of rubber powder and coal powder. The kinetic parameters of the pyrolysis reaction would also be obtained.

\section{Methodology}

\subsection{Materials}

The waste tires (truck tires, liners and nylon tires) are obtained from Nantong Huili Rubber Co., Ltd. They were ground and sieved to obtain rubber powders with different sizes of 12 mesh, 26 mesh, 40 mesh, and 60 mesh. 12-mesh, 26-mesh, 40-mesh, and 60-mesh of truck tire powders referred to as TTP12, TTP26, TTP40, TTP60. 26-mesh of liner powder and 26-mesh of nylon tire powder are referred to as LP26 and NTP26, respectively. The pulverized coal used in this study is obtained from the Zhundong Coal Mine, which the combustion characteristics are close to that of lignite. The pulverized coal was also obtained by grinding and screening as a test sample. Three kinds of blends with different weight percentage of the rubber powder to pulverized coal were prepared $(10 \%, 20 \%$ and $40 \%)$ and dried in an oven at $363 \mathrm{~K}$ for 2 hours.

\subsection{Thermogravimetric analysis (TGA)}

Thermogravimetric analysis (TGA) is used to measure the relationship between the mass of a sample and temperature or time. The heating rate, holding time, atmosphere, etc. of the thermogravi can be controlled by changing the relevant parameters in the software. The sample containing the crucible was placed in a thermogravimetric analyzer (TGA/DSC2) to test the weight of the sample continuously. The weight of the sample is $10 \mathrm{mg}$ each time. The crucible used in the experiment is $\mathrm{Al}_{2} \mathrm{O}_{3}$ ceramic crucible. The pyrolysis temperature is in the range of $50-1000{ }^{\circ} \mathrm{C}$. The heating rate is controlled at $20{ }^{\circ} \mathrm{C} / \mathrm{min}$. The experiment was carried out in a nitrogen atmosphere at a flow rate of 25 $\mathrm{ml} / \mathrm{min}$. Three replicate experiments were performed to ensure reproducibility of each run, and the results showed good reproducibility with deviations generally below $1.0 \%$.

\subsection{Kinetic methods}

The reaction rate is defined as the derivative of the conversion rate for time. According to the law of mass action, the pyrolysis rate equation of the sample can be obtained as follows [23]:

$$
\frac{d \alpha}{d t}=k f(\alpha)
$$

Where $\mathrm{k}$ is the kinetic constant and can be described by Arrhenius's law:

$$
k=A \exp (-E / R T)
$$

Heating rate is defined as follows:

$$
\beta=d T / d t
$$

In the above formula (1) - (3), t, T, $\alpha, \mathrm{f}(\alpha), \mathrm{A}, \mathrm{E}$ and $\mathrm{R}$ represent the time $(\mathrm{min})$, temperature $(\mathrm{K})$, conversion rate, differential form reaction mechanism function, prefactor, activation energy $(\mathrm{kJ} / \mathrm{mol})$ and gas constant $(8.314 \mathrm{~J} /(\mathrm{K} \mathrm{mol}))$, respectively. The pyrolysis conversion rate of the sample can be obtained from the weight loss curve (TG):

$$
\alpha=\frac{W_{0}-W_{t}}{W_{0}-W_{f}}
$$

Where $\mathrm{W}_{0}$ is the initial mass, $\mathrm{W}_{\mathrm{t}}$ for the mass at time $\mathrm{t}$ and $\mathrm{W}_{\mathrm{f}}$ for the terminal mass. The functional form of $\mathrm{f}$ $(\alpha)$ depends on the type of reaction or the reaction mechanism.

The function $f(\alpha)$ is generally independent on temperature $(\mathrm{T})$ and time $(\mathrm{t})$ and it is only related to the degree of reaction $(\alpha)$. For a simple response $f(\alpha)$ can be expressed as:

$$
f(\alpha)=(1-\alpha)^{n}
$$

According to Equ. (1) - (5), the following equation can be obtained.

$$
d \alpha=A \exp (-E / R T)(1-\alpha)^{n} d t
$$

The equation of Coats and Redfern (CR) [24-26] is applied to the integration of Equ. (6):

$$
\int_{0}^{\infty} \frac{d \alpha}{1-\alpha}=\frac{A}{\beta} \int_{T_{0}}^{T} e^{-E / R T} d T
$$

According to the literature $[17,27,28], \mathrm{n}$ equals 1 and Equ. (8) can be calculated by integrating and sorting the Equ. (7).

$$
\begin{aligned}
& \ln \left[-\frac{(1-\alpha)}{T^{2}}\right]=\ln \left[\frac{A R}{\beta E}\left(1-\frac{2 R T}{E}\right)\right]-\frac{E}{R T} \\
& \text { Order } a=\ln \left[\frac{A R}{\beta E}\left(1-\frac{2 R T}{E}\right)\right] . \text { In the range of the }
\end{aligned}
$$

experimental temperature, $a$ can be regarded as a constant. Make $Y=\ln \left[\ln T^{2}-\ln (1-\alpha)\right], b=-E / R, x=1 / T$, then the function can be written as:

$$
Y=a+b x
$$

After obtaining the values of $a$ and $b$ by Equ. (9), the requency factor $(\mathrm{A})$ and the frapparent activation energy (E) can be calculated. 


\section{Results and discussion}

\subsection{Characteristics of materials}

The results of elemental analysis and proximate analysis of truck tires, liners, nylon tires and coal are shown in Table 1, which also shows the heating value. The results indicate that used tires contain more carbon and less moisture than coal. There are not many substances such as sulfur and nitrogen in used tires. The volatile matter in used tires is about twice that of coal. Besides, the amount of ash is low, so that the treatment of ash will be much more convenient. The heating value of used tires is significantly higher than that of coal. In summary, the use of used tires as fuel has its unique advantages.

Table 1. Characteristic of used tires and coal.

\begin{tabular}{|c|c|c|c|c|}
\hline Material & $\begin{array}{c}\text { Truck } \\
\text { tire }\end{array}$ & Liner & $\begin{array}{c}\text { Nylon } \\
\text { tire }\end{array}$ & Coal \\
\hline \multicolumn{5}{|c|}{ Elemental analysis (wt.\%, as received basis) } \\
\hline $\mathrm{C}$ & 82.57 & 78.89 & 82.25 & 74.62 \\
\hline $\mathrm{H}$ & 6.42 & 5.71 & 6.29 & 3.11 \\
\hline $\mathrm{O}$ & 7.88 & 12.08 & 8.59 & 18.38 \\
\hline $\mathrm{N}$ & 0.60 & 0.51 & 0.75 & 0.61 \\
\hline $\mathrm{S}$ & 1.93 & 2.32 & 1.62 & 0.70 \\
\hline Moisture (M) & 0.60 & 0.49 & 0.50 & 2.58 \\
\hline \multicolumn{5}{|c|}{ Proximate analysis (wt.\%,dry basis) } \\
\hline $\begin{array}{c}\text { Volatile matter } \\
\text { (VM) }\end{array}$ & 61.79 & 60.75 & 63.56 & 31.74 \\
\hline Fixed carbon (FC) & 32.57 & 28.60 & 30.4 & 56.21 \\
\hline Ash & 5.64 & 10.65 & 6.04 & 12.05 \\
\hline $\begin{array}{l}\text { Heating value } \\
(\mathrm{KJ})\end{array}$ & 34.70 & 31.18 & 33.41 & 26.31 \\
\hline
\end{tabular}

\subsection{Pyrolysis characteristics of the sample}

The TGA and DTG curves for four different sizes of truck tire powders are shown in Fig. 1. The pyrolysis process is characterized by three stages, and the sample decomposition mainly occurs to stage two. Their curve laws are very close. The four-size truck tire powder starts pyrolysis at around $310{ }^{\circ} \mathrm{C}$ and completes pyrolysis at around $480{ }^{\circ} \mathrm{C}$. The peak temperature is approximately $390{ }^{\circ} \mathrm{C}$. The decomposition strengths are not much different, and there is a slight increase as the particle size of the rubber powder increases. The results show that the particle size of the rubber powder has little effect on the pyrolysis of the rubber.

Fig. 2 shows the TGA and DTG curves for TTP26, LP26, NTP26 and coal. The weight loss caused by pyrolysis of used tires mainly occurs between $310^{\circ} \mathrm{C}$ and $480{ }^{\circ} \mathrm{C}$. In the DTG curve, sharp peaks between $350{ }^{\circ} \mathrm{C}$ and $400^{\circ} \mathrm{C}$ should be associated with the decomposition of natural rubber (polyisoprene, NR) generally beneficial to the production of petroleum distinct peak (Fig. 2a and 2b). NTP26 showed a second distinct peak at $450{ }^{\circ} \mathrm{C}$ except for the first peak at $394{ }^{\circ} \mathrm{C}$ (Fig. 2c). This is because the nylon rubber contains more synthetic rubber components. Therefore, unlike the three-stage pyrolysis of truck tires and liners, nylon tires have a four-stage pyrolysis (Fig.2). The intense pyrolysis of coal mainly occurs at $400-520{ }^{\circ} \mathrm{C}$, and then slowly degrades until at about $830{ }^{\circ} \mathrm{C}$ to end pyrolysis. The temperature at the fastest pyrolysis rate is $460{ }^{\circ} \mathrm{C}$, which is higher than that of used tires. However, the decomposition intensity of the coal is much lower than that of used tires. This is because the pyrolysis temperature peak of used tires is derived from the decomposition of rubber, while the pyrolysis temperature peak of coal is caused by the volatilization of coal. The coal has a high fixed carbon content, so it does not decompose rapidly during pyrolysis.
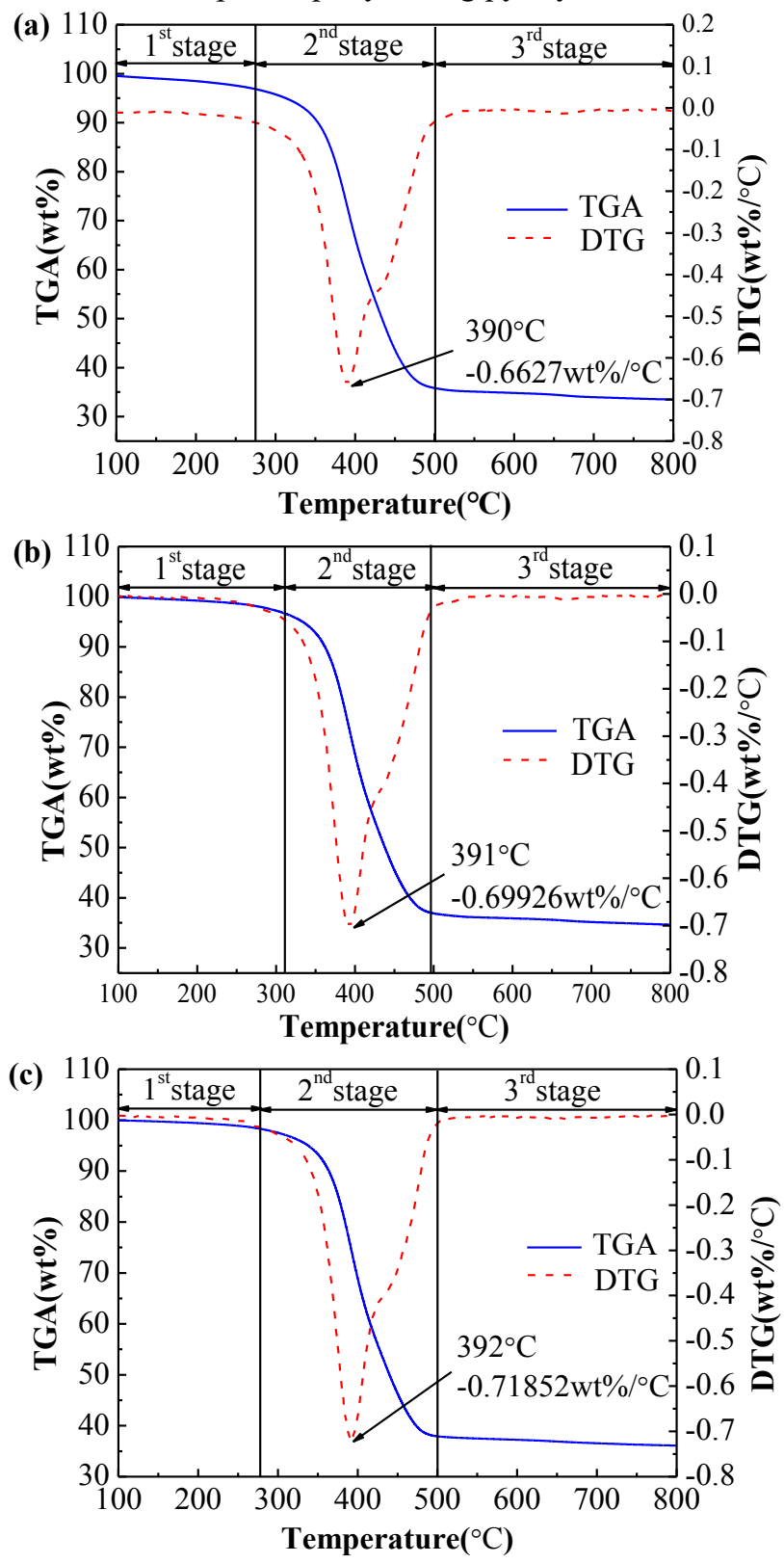
(d)

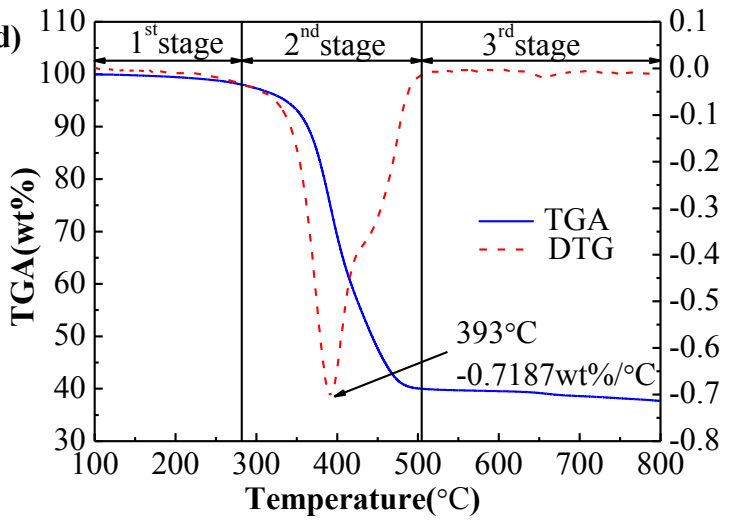

Fig. 1. TGA and DTG curves of truck tire of different sizes. (a) TTP12, (b) TTP26, (c) TTP40, (d) TTP60.
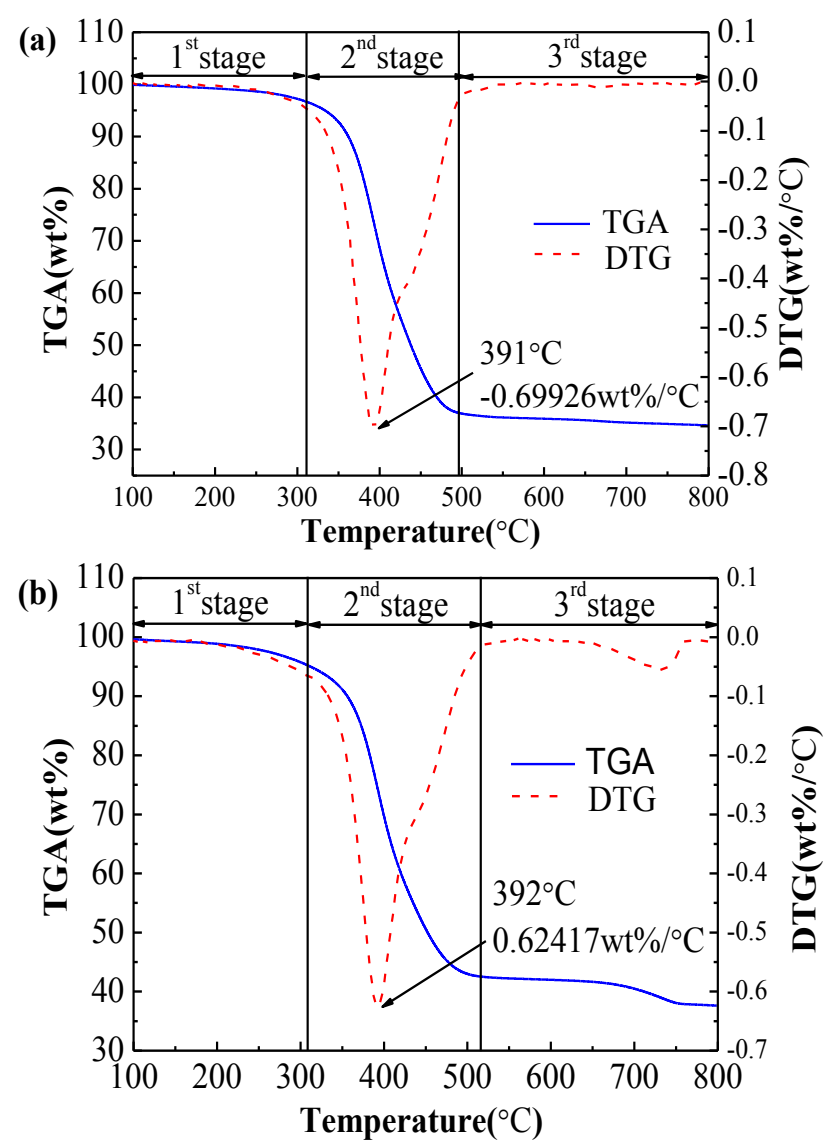
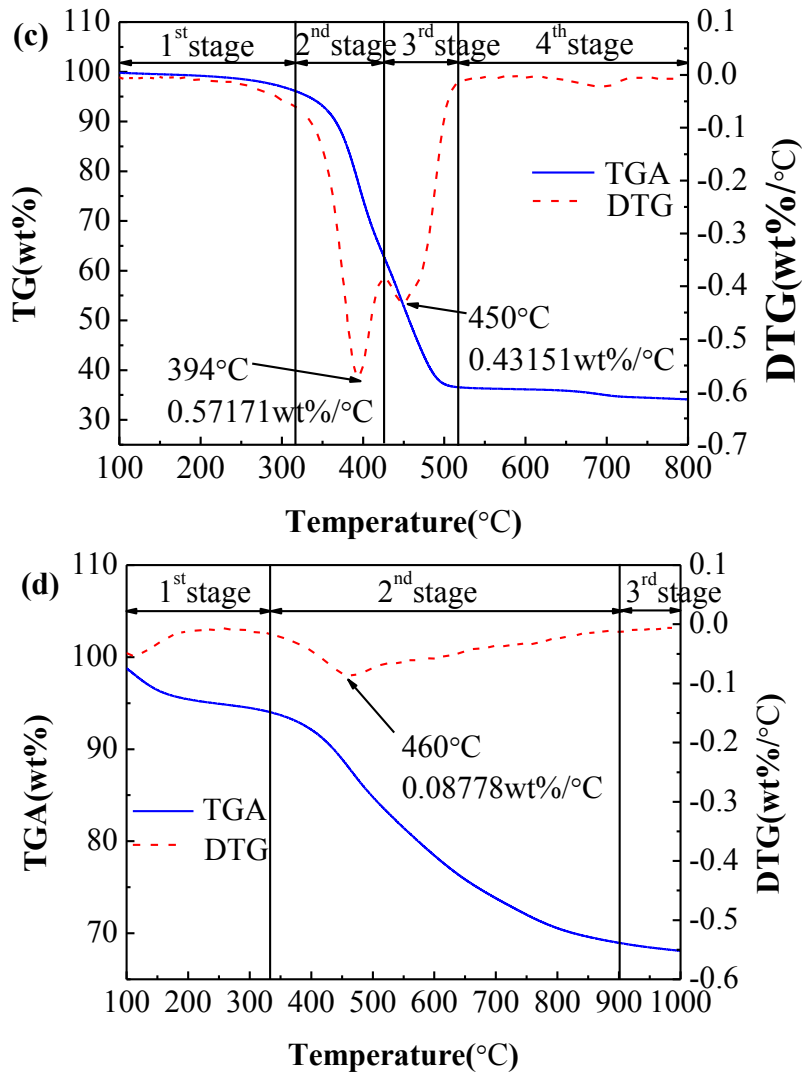

Fig. 2. TGA and DTG curves of used tires of different types. (a) TTP26, (b) LP26, (c) LTP26, (d) coal.

\subsection{Pyrolysis of the fuel blends}

Fig. 3 and Fig. 4 show TGA and DTG curves of TTP26 mixed with the coal and LP26 mixed with the coal. The content of the rubber powder is $10 \mathrm{wt} . \%, 20 \mathrm{wt} . \%, 40$ wt. $\%$, respectively. When the content of the rubber powder is 10 wt.\% (Fig. 3a and Fig. 4a), the pyrolysis temperature of blends is close to that of coal. The first peak temperature is same as the peak temperature of rubber powder when it is separately pyrolyzed, where the pyrolysis of the rubber powder is mainly considered. The second peak appears between $430{ }^{\circ} \mathrm{C}$ and $460{ }^{\circ} \mathrm{C}$, wthe temperature at which coal powder ends pyrolysis. When the content of the rubber powder is $20 \mathrm{wt} . \%$ (Fig. $3 \mathrm{~b}$ and Fig. 4b), the temperature at which the blends starts to pyrolyze is slightly lowered. There is no second obvious peak. At $430-460{ }^{\circ} \mathrm{C}$, the weight loss rate is relatively close. The rate of weight loss between $460{ }^{\circ} \mathrm{C}$ and $520^{\circ} \mathrm{C}$ is decreasing at a higher rate. After that, the DTG curve gradually stabilizes and the remaining volatiles slowly precipitate. When the content of rubber powder is 40 wt.\% (Fig. 3c and Fig. 4c), the temperature at which pyrolysis starts is closer to the pyrolysis temperature of the rubber powder. As the content of rubber powder increases, the intensity of the peak appearing in the 2nd stage becomes stronger. 

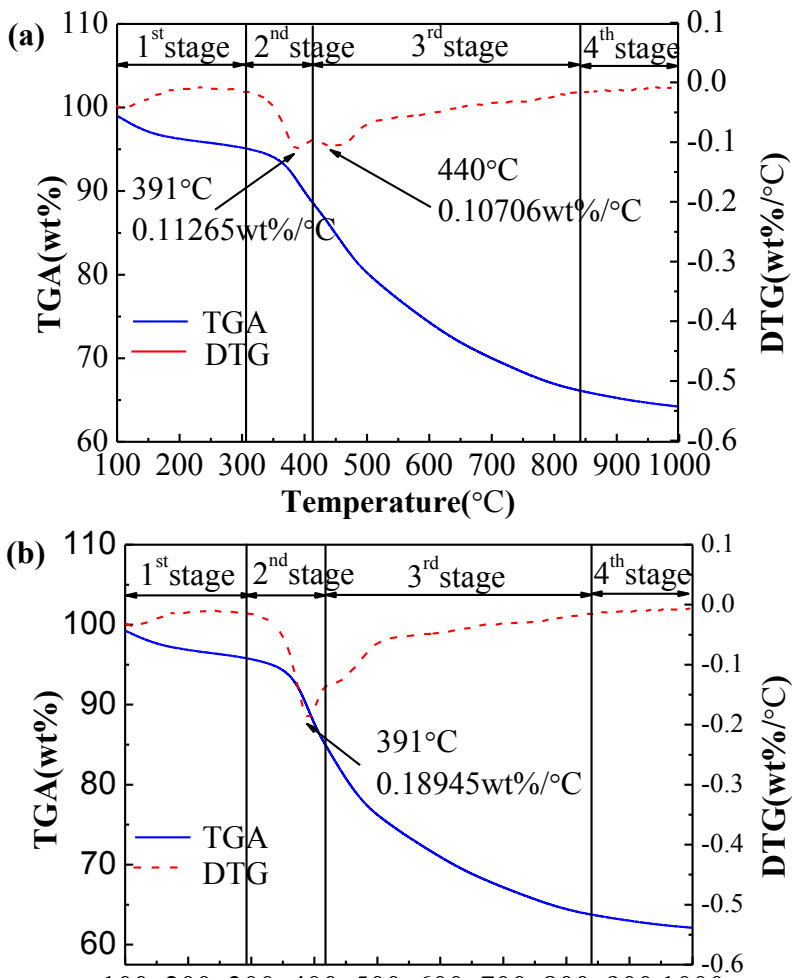

1002003004005006007008009001000

Temperature $\left({ }^{\circ} \mathrm{C}\right)$

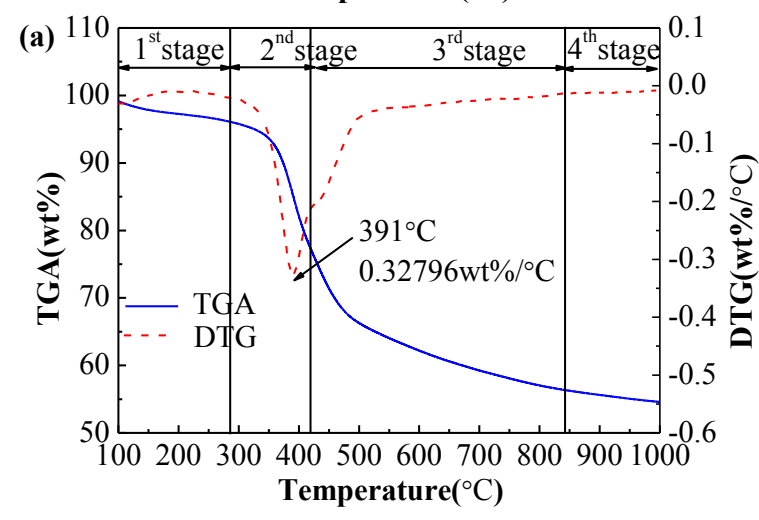

Fig. 3. TGA and DTG curves of the blends with different ratios of TTP26 (a) 10 wt.\%, (b) 20 wt.\%, (c) 40 wt.\%.

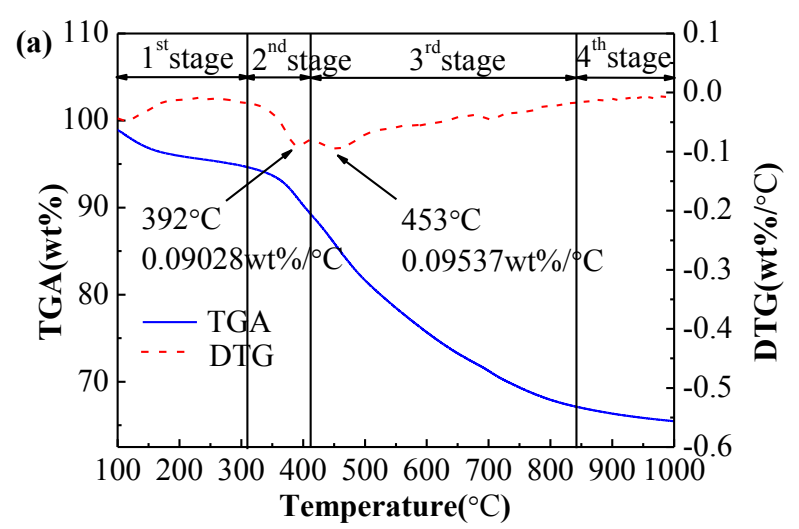

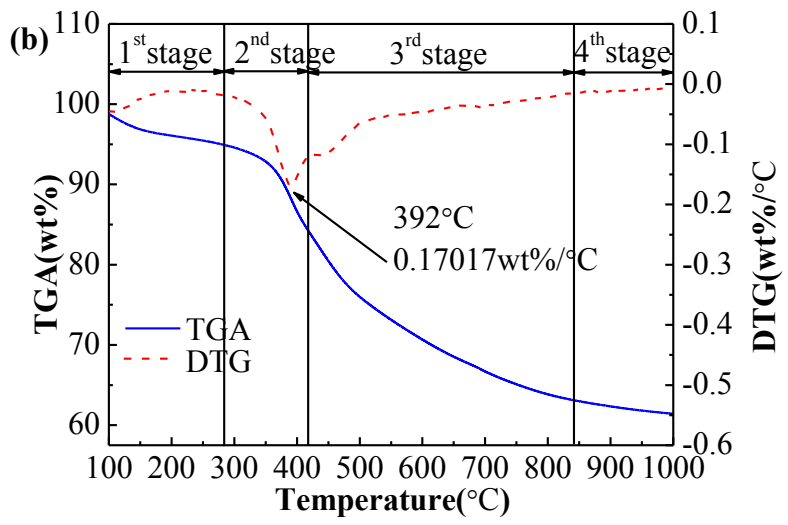

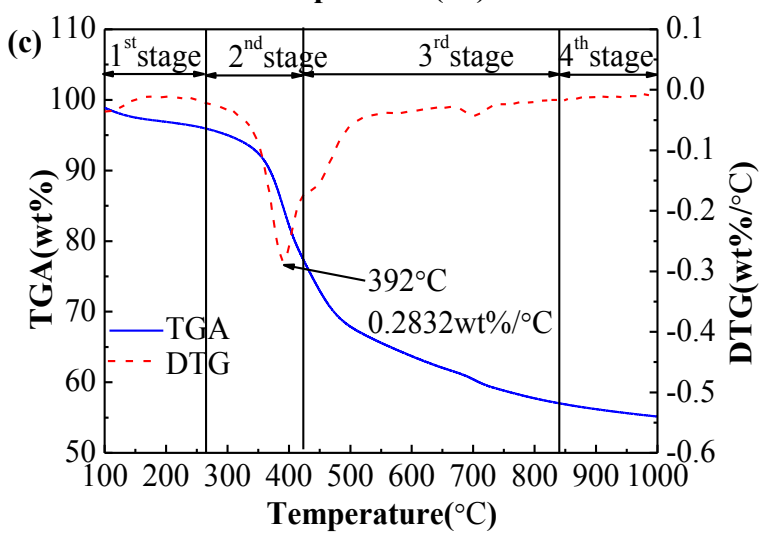

Fig. 4. TGA and DTG curves of the blends with different ratios of LP26. (a) 10 wt.\%, (b) 20 wt.\%, (c) 40 wt.\%

Fig. 5 is a graph obtained by pyrolysis of the NTP26 mixed with the coal. In the pyrolysis curves of the above two blends, the biggest difference is that the DTG curve of the blends of NTP26 and the coal each has two distinct peaks, no matter what the mixtures ratio is. The first peak is mainly due to the decomposition of the rubber powder. The second peak temperature appeared at $453{ }^{\circ} \mathrm{C}$. When the rubber content is low (Fig. 5a), the weight loss rate of the second peak point exceeds the weight loss rate of the first peak point. This is because, not only the pyrolysis of pulverized coal is involved, but also the pyrolysis of synthetic rubber is participated. As the content of the rubber powder increases (Fig. $5 b$ and $5 c$ ), the intensity of the two peak points gradually increases and the weight loss rate of the first peak point gradually exceeds the weight loss rate of the second peak point. 

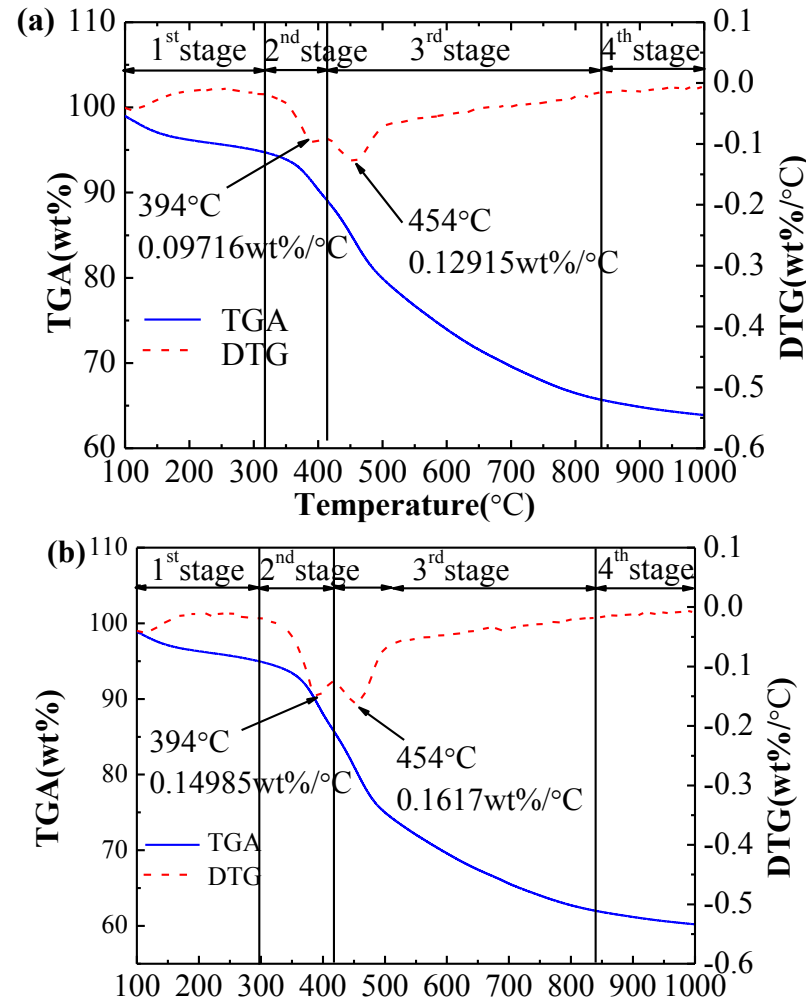

Temperature $\left({ }^{\circ} \mathrm{C}\right)$

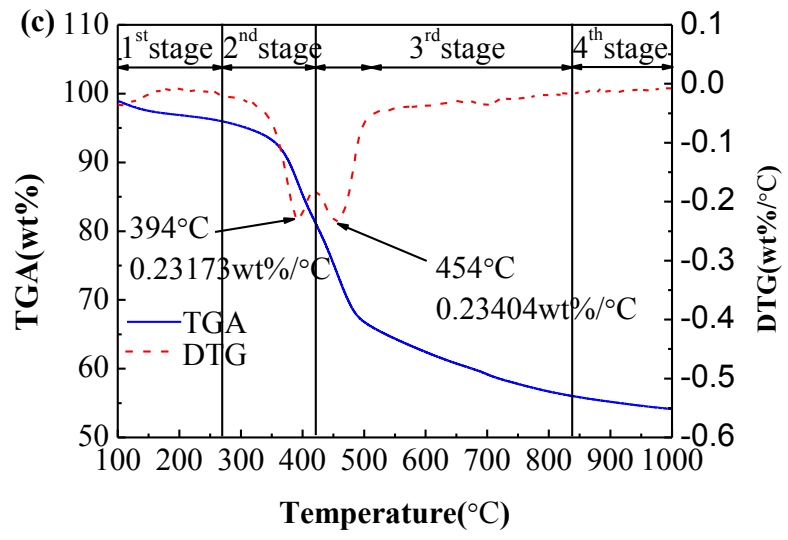

Fig. 5. TGA and DTG curves of the blends with different ratios of LTP26. (a) 10 wt.\%, (b) 20 wt.\%, (c) 40 wt.\%

\subsection{Interaction of rubber and coal}

As discussed above, the peaks are basically reflected in the curve of the mixture pyrolysis when the substance is separately pyrolyzed. The peak temperature of the DTG curve is substantially same as the peak temperature of the mixture DTG curve when the sample is pyrolyzed separately. This result indicates that the pyrolysis process of the samples did not change significantly due to the mixing of the samples in the thermogravimetric analysis. By the quation $W_{\text {mix }}(T)=f_{\mathrm{A}} W_{\mathrm{A}}(T)+f_{\mathrm{B}} W_{\mathrm{B}}(T)\left(W_{\text {mix }}\right.$, $W_{\mathrm{A}}$, and $W_{\mathrm{B}}$ are the masses of the blends, fuel $\mathrm{A}$, and fuel $\mathrm{B}$, respectively, and $f_{\mathrm{A}}$ and $f_{\mathrm{B}}$ are the mass ratios of the single components in the blends), the calculated TGA and DTG curves for the samples at different ratios are shown in Fig. 6 and Fig. 7. The maximum error of the solid residue does not exceed $1 \%$, and the maximum temperature error of the peak point is $7{ }^{\circ} \mathrm{C}$ (Table2). This shows that there is almost no interaction between the rubber powder and the pulverized coal mixture during the pyrolysis process. Some errors may be caused by the uneven mixing and sampling of the materials during the mixing ratio.
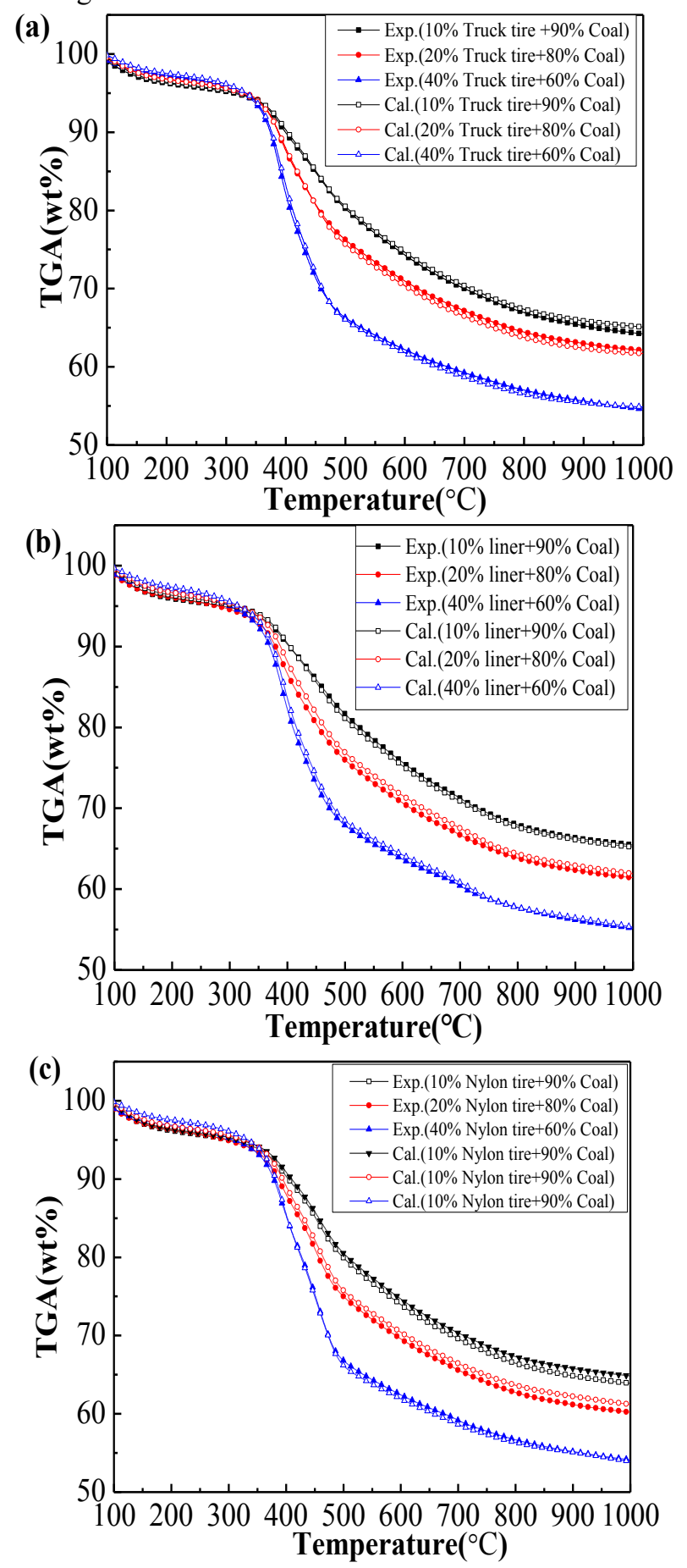

Fig. 6. Calculated and experimental of the TGA curves of the blends with different types of used tires. (a) TTP26, (b) LP26, (c) NTP26. 

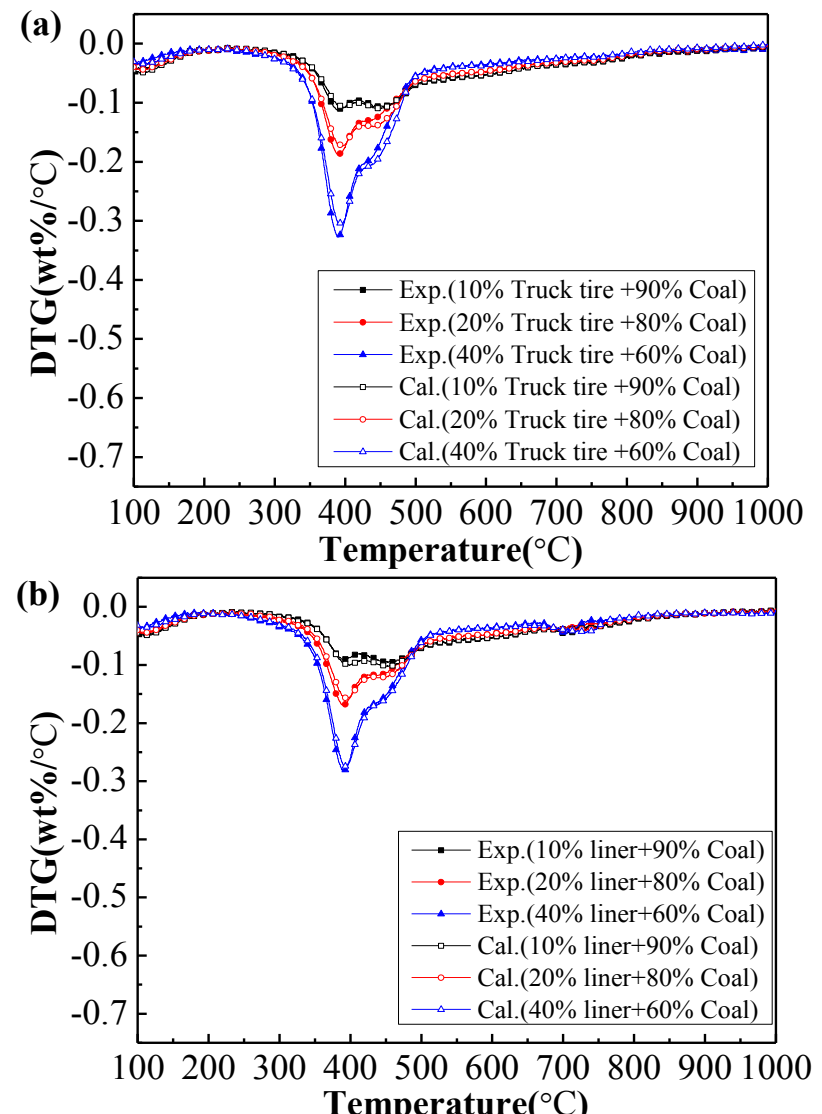

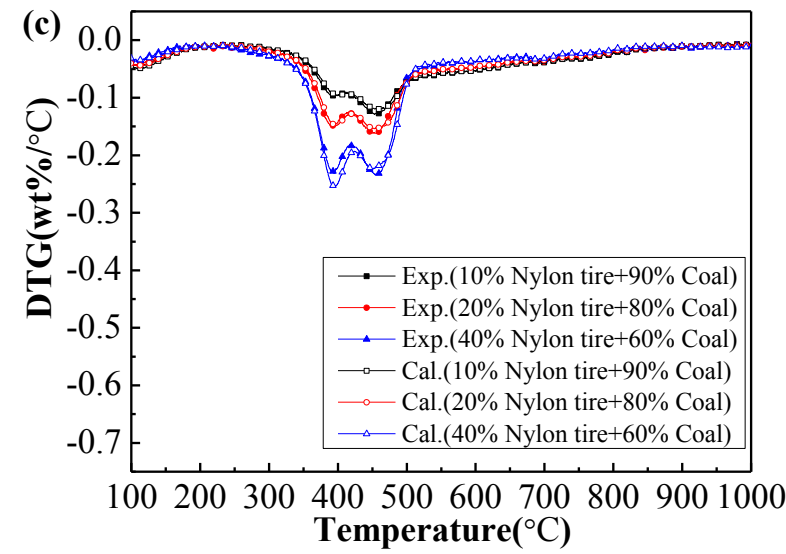

Fig. 7. Calculated and experimental of the DTG curves of the blends with different types of used tires. (a) $\mathrm{TTP}_{26}$, (b) $\mathrm{LP}_{26}$, (c) $\mathrm{NTP}_{26}$

Table 2. Parameters comparison between the calculated and experimental TGA curves

\begin{tabular}{|c|c|c|c|c|c|c|c|c|c|}
\hline \multirow{2}{*}{ Sample } & \multicolumn{3}{|c|}{ First peak } & \multicolumn{3}{|c|}{ Second peak } & \multicolumn{3}{|c|}{ solid residue } \\
\hline & $\begin{array}{l}\text { Exp. } \\
\left({ }^{\circ} \mathrm{C}\right)\end{array}$ & $\begin{array}{l}\text { Cal. } \\
\left({ }^{\circ} \mathrm{C}\right)\end{array}$ & $\begin{array}{l}\text { Relative } \\
\text { error }\left({ }^{\circ} \mathrm{C}\right)\end{array}$ & $\begin{array}{l}\text { Exp. } \\
\left({ }^{\circ} \mathrm{C}\right)\end{array}$ & $\begin{array}{l}\text { Cal. } \\
\left({ }^{\circ} \mathrm{C}\right)\end{array}$ & $\begin{array}{l}\text { Relative } \\
\text { error }\left({ }^{\circ} \mathrm{C}\right)\end{array}$ & $\begin{array}{l}\text { Exp. } \\
(\%)\end{array}$ & $\begin{array}{l}\text { Cal. } \\
(\%)\end{array}$ & $\begin{array}{l}\text { Relative } \\
\text { error(\%) }\end{array}$ \\
\hline \multicolumn{10}{|c|}{ Truck tire (wt. \%) } \\
\hline $10 \%$ & 391 & 398 & 7 & 440 & 447 & 7 & 64.2 & 65.1 & 0.9 \\
\hline $20 \%$ & 391 & 395 & 4 & - & - & - & 62.1 & 61.7 & 0.4 \\
\hline $40 \%$ & 391 & 395 & 4 & - & - & - & 54.6 & 54.9 & 0.3 \\
\hline \multicolumn{10}{|c|}{ Liner (wt. \%) } \\
\hline $10 \%$ & 392 & 399 & 7 & 453 & 454 & 0 & 65.5 & 65.2 & 0.3 \\
\hline $20 \%$ & 392 & 394 & 2 & - & - & - & 61.4 & 61.9 & 0.5 \\
\hline $40 \%$ & 392 & 392 & 0 & - & - & - & 55.2 & 55.3 & 0.1 \\
\hline \multicolumn{10}{|c|}{ Nylon tire (wt. \%) } \\
\hline $10 \%$ & 394 & 398 & 4 & 454 & 460 & 6 & 63.9 & 64.9 & 1 \\
\hline $20 \%$ & 394 & 396 & 2 & 454 & 454 & 0 & 60.2 & 61.2 & 1 \\
\hline $40 \%$ & 394 & 396 & 2 & 454 & 450 & 4 & 54.1 & 53.9 & 0.2 \\
\hline
\end{tabular}




\subsection{Kinetics analysis}

The pyrolysis of tires, coal and fuel blends occurs mainly in the 2 nd and 3 rd stages. Table 3 shown the activation energy, pre-exponential factor, and correlation coefficients for all fuels in these two stages. Regardless of the stage, the correlation coefficient $\mathrm{R}^{2}$ is not lower than 0.97 , which reflects that the pyrolysis process of these two stages has a good correlation. In the 2nd stage, both pre-exponential factor and activation energy values have a downward trend when the coal content increases. Since the degree of pyrolysis with coal is weaker than the pyrolysis of the rubber powder, the activation energy goes down as the content of the rubber powder decreases. Compared to rubber powder, the reactivity of coal is lower, that's why the pre-exponential factor decreases as the coal powder content increases. Synthetic rubber and coal dominated the 3rd stage of the pyrolysis. As truck tires and liners contain less synthetic rubber, the 3rd stage mainly depends on pyrolysis of coal when the content of pulverized coal in the blends is large. As the pulverized coal content decreases, the activation energy decreases slightly. When the content of rubber powder in the blends is large, the pyrolysis of synthetic rubber occurs obviously. The activation energy also increases as the content of the rubber powder increases. Nylon tires contain more synthetic rubber, which is different from the above two rubber powders. Even if the nylon tire rubber powder content in the blends is low, the pyrolysis of synthetic rubber can be reflected in the 3rd stage, so that the pulverized coal reduces the activation energy. The activation energy is mainly determined by the synthetic rubber in the 3rd stage. Nylon tires contain the highest amount of synthetic rubber relatively, resulting in the highest activation energy of nylon tires. Since truck tires contain more rubber (natural rubber and synthetic rubber), truck tires have higher activation energy in overall process of pyrolysis.

Table 3. Chemical kinetic parameters of used tires, coal and fuel blends.

\begin{tabular}{|c|c|c|c|c|}
\hline Sample & $\begin{array}{c}\text { Temperature } \\
\left({ }^{\circ} \mathrm{C}\right)\end{array}$ & $\begin{array}{c}\mathrm{E} \\
\left(\mathrm{kJ} \mathrm{mol}^{-1}\right)\end{array}$ & $\begin{array}{c}\mathrm{A} \\
\left(\mathrm{min}^{-1}\right)\end{array}$ & $\mathrm{R}^{2}$ \\
\hline \multirow{2}{*}{$\begin{array}{l}\text { Truck tire } \\
(10 w t \%)\end{array}$} & $450-410$ & 34.00 & $3.76 \times 10^{1}$ & 0.99 \\
\hline & $410-480$ & 28.03 & $2.30 \times 10^{1}$ & 1 \\
\hline \multirow{2}{*}{$\begin{array}{l}\text { Truck tire } \\
(20 \mathrm{wt} \%)\end{array}$} & $340-420$ & 50.08 & $9.97 \times 10^{2}$ & 0.98 \\
\hline & $420-480$ & 27.09 & $1.42 \times 10^{1}$ & 0.99 \\
\hline \multirow{2}{*}{$\begin{array}{l}\text { Truck tire } \\
(40 \mathrm{wt} \%)\end{array}$} & $325-425$ & 64.94 & $2.13 \times 10^{4}$ & 0.98 \\
\hline & $425-480$ & 29.34 & $2.95 \times 10^{1}$ & 0.98 \\
\hline \multirow{2}{*}{$\begin{array}{l}\text { Truck tire } \\
(100 \mathrm{wt} \%)\end{array}$} & $310-425$ & 89.39 & $2.71 \times 10^{6}$ & 0.98 \\
\hline & $425-480$ & 61.24 & $1.64 \times 10^{4}$ & 1 \\
\hline \multirow{2}{*}{$\begin{array}{c}\text { Liner } \\
(10 w t \%)\end{array}$} & $450-410$ & 26.04 & $8.15 \times 10^{0}$ & 0.98 \\
\hline & $410-480$ & 25.37 & $7.83 \times 10^{0}$ & 1 \\
\hline \multirow{2}{*}{$\begin{array}{c}\text { Liner } \\
(20 \mathrm{wt} \%)\end{array}$} & $340-420$ & 39.56 & $1.41 \times 10^{2}$ & 0.98 \\
\hline & $420-480$ & 23.94 & $5.33 \times 10^{0}$ & 1 \\
\hline \multirow{2}{*}{$\begin{array}{c}\text { Liner } \\
(40 w t \%)\end{array}$} & $325-425$ & 53.50 & $2.42 \times 10^{3}$ & 0.98 \\
\hline & $425-480$ & 26.41 & $1.65 \times 10^{1}$ & 0.99 \\
\hline \multirow{2}{*}{$\begin{array}{l}\text { Truck tire } \\
(100 w t \%)\end{array}$} & $310-425$ & 72.46 & $1.08 \times 10^{5}$ & 0.97 \\
\hline & $425-480$ & 38.88 & $2.39 \times 10^{2}$ & 0.99 \\
\hline \multirow{2}{*}{$\begin{array}{l}\text { Nylon tire } \\
(10 w t \%)\end{array}$} & $450-410$ & 27.86 & $1.08 \times 10^{1}$ & 0.98 \\
\hline & $410-480$ & 33.40 & $3.28 \times 10^{1}$ & 1 \\
\hline Nylon tire & $340-420$ & 36.94 & $7.17 \times 10^{1}$ & 0.98 \\
\hline
\end{tabular}

\begin{tabular}{|c|c|c|c|c|}
\hline$(20 \mathrm{wt} \%)$ & $420-480$ & 36.99 & $7.63 \times 10^{1}$ & 1 \\
\hline Nylon tire & $325-425$ & 46.92 & $5.28 \times 10^{2}$ & 0.97 \\
\cline { 2 - 5 }$(40 \mathrm{wt} \%)$ & $425-480$ & 46.51 & $5.14 \times 10^{2}$ & 1 \\
\hline Nylon tire & $310-425$ & 75.66 & $1.48 \times 10^{5}$ & 0.97 \\
\cline { 2 - 5 }$(100 \mathrm{wt} \%)$ & $425-480$ & 62.75 & $1.15 \times 10^{4}$ & 1 \\
\hline coal & $400-520$ & 23.27 & $5.60 \times 10^{0}$ & 0.99 \\
\hline
\end{tabular}

\section{Conclusions}

In this study, three kinds of rubber powders and copyrolysis of the blends of rubber and coal powder were examined by thermogravimetric analysis. The results show that the particle size of the rubber powder has little effect on the pyrolysis characteristics, and the pyrolysis process of a single material has three stages, except for nylon tires exhibiting a four-stage reaction due to the relatively more synthetic rubber contained in it. When the rubber powder is mixed with pulverized coal, the three-stage reaction of the pyrolysis process alters to the four-stage one. The mixing ratio of the materials has an obvious effect on pyrolysis. As the proportion of coal powder in the blends increases, the weight loss curve shifts to the right. The increase in the pulverized coal proportion causes the second peak on the DTG curve higher, and the rate of weight loss at the second peak point will eventually exceed the first peak point. The results of the analysis show that, there is no interaction between the rubber powder and the coal powder during the pyrolysis of the blends. The superposition of the pyrolysis characteristics of the one-component substance can express the pyrolysis characteristics of the blends. The study of the kinetics of the blends shows that a decrease in the coal causes the activation energy increasing in the 2nd stage. For the blends of coal with truck tires and liners, the increase in the rubber powder content causes the activation energy decreasing in the 3rd stage when the pulverized coal content is high. When the content of the rubber powder is large, the increase of the rubber powder causes an increase in the activation energy. This is because the co-pyrolysis kinetics is mainly affected by the natural rubber in the rubber powder in the 2nd stage, and the synthetic rubber in the 3rd stage. For the blends of coal and nylon tires, the activation energy increases with the increase of the rubber powder in both the 2 nd and 3rd stages due to the inclusion of more synthetic rubber. Compared to the other two samples, the activation energy of the nylon tires is higher in the 3rd stage. Nevertheless, truck tires have higher activation energy because of higher rubber content, during the entire pyrolysis process.

\section{Acknowledgments}

This work was economically supported by the Capacity Building Project in Local Universities of Science and Technology Commission of Shanghai Municipality (No.19020500900) and the Key Technological Research Project of Science and Technology Commission of Shanghai Municipality (No.18DZ1202502). 


\section{References}

1. Inrnational Energy Agency, World Energy, Outlook, (2011)

2. Ke Miao Lu, W. Jhy Lee, W. H. Chen, T. C. Lin, Appl. Energy, 105, 57-65 (2013)

3. Y. F. Liao, X. Q. Ma, Appl. Energy, 87, 35263532 (2010)

4. European tyre and rubber manufacturers association, End-of-life Tyre REPORT2015, Brussels, Belgium, (2015)

5. Rubber manufacturers association, 2015 US scrap tire management summary, Washington DC, USA, (2016)

6. China resource recycling association, 2018 China renewable resources recycling industry development report, Shang-hai, China, (2018)

7. J. Kandasamy, I.Gökalp, ENERG FUEL, 29, 346354 (2015)

8. P. Rathsack, F. Riedewald, M. Jose Sousa-Gallagher, J ANAL APPL PYROL, 116, 49-57 (2015)

9. V.Torretta, E.C.Rada, M.Ragazzi, E.Trulli Waste Manag, 45, 152-160 (2015)

10. J. R. Lanteigne, J. P. Laviolette, J. Chaok, ENERG FUEL. 29, 763-774 (2015)

11. D. Czajczyńska, R. Krzyżyńska, H. Jouhara, N. Spencer, ENERGY, 134, 1121-1131 (2017)

12. J.Gronowicz, T. Kubiak, Probl Eksploat. 2, 5-17 (2007)

13. D.Y.Leung, C. Wang,J ANAL APPL PYROL, 45, 153-169 (1998)

14. M.Sienkiewicz, J.Kucinska-Lipka, H. Janik, A. Balas, Waste Manag. 32, 1742-1751 (2012)

15. P. T. Williams, S. Besler, D. T. Taylor, FUEL, 69, 1479-1482 (1990)
16. P. T. Williams, S. Besler, FUEL. 74, 1277-1283 (1995)

17. Y. Tang, C.W. Curtis, ENERG FUEL.37, 195-215 (1996)

18. P. Ariyadejwanich, W.Tanthapanichakoon, K.Nakagawa, S. R. Mukai, CARBON. 41, 157-164 (2003)

19. J. D.Martinez, N. Puy, R. Murillo, T. Garcia, RENEW SUST ENERG REV, 23, 179-213 (2013)

20. E. Aylón, A. Fernández-Colino, R.Murillo, M.V. Navarro, IND ENG CHEM RES, 47, 4029-4033 (2008)

21. J. D. Martínez, R. Murillo, T. García, I. Arauzo, ENERG CONVERS MANAGE, 81, 338-353 (2014)

22. L. Lombard, E. Carnevale. A. Corti, Waste Management, 27, 26-44 (2015)

23. Y. Ma, S.Y. Li, FUEL PROCESS TECHNOL, 100, 11-15. (2012)

24. A.V. Coats, J.P. Redfern, Nature, 201, 68-69 (1964)

25. J.Guo, A.C. Lua, BIOMASS BIOENERG. 20, 223223 (2001)

26. H. Sai, A. Hussain, A, Salema,BIORESOURCE TECHNOL, 118, 382-389 (2012)

27. D. W. Brazier, N. V. Schwartz, J APPL POLYM SCI, 22, 113-124 (1978)

28. D.Y.C Leung, C.L Wang, J ANAL APPL PYROL.45, 153-169 (1998)

29. I.F. Elbaba, C. F. Wu, P.T. Williams. ENERG FUEL, 24, 3928-3935 (2010)

30. L. Zhang; B. Zhou; P. G. Duan; F. Wang, CHEM ENG J, 285, 157-163 (2016)

31. S. Galvagno, S. Casu,M. Martino, E. D. Palma, J THERM ANAL CALORIM, 88, 507-514 (2007) 